\section{Negativity: space, politics and affects}

\section{Thomas Dekeyser}

Royal Holloway University of London, UK

\title{
Anna Secor
}

Durham University, UK

\section{Mitch Rose}

Aberystwyth University, UK

\section{David Bissell}

University of Melbourne, Australia

\author{
Vickie Zhang \\ Guangzhou University, the People's Republic of China
}

\section{Jose Luis Romanillos}

Exeter University, UK

\begin{abstract}
This paper reflects on the status of 'negativity' in contemporary social and geographical thought. Based on a panel discussion held at the American Association of Geographers Annual Meeting 202I, each contributor discusses what negativity means to them, and considers its various legacies and potential future trajectories. Along the way, the contributors offer ways of attending to negative spaces (voids, abysses, absences), affects (vulnerabilities, sad passions, incapacities, mortality) and politics (impasses, refusals, irreparabilities). However, rather than defining negativity narrowly, the paper stays with the diversity of work on negativity being undertaken by geographers and other scholars, discussing how varying perspectives expand or dismantle particular elements within spatial theory. Collectively, the contributors argue for paying attention to negativity as the faltering, failure or impossibility of relations between body and world, thus situating it in conversation with relational thought, vitalist philosophies and affirmative ethics.
\end{abstract}




\section{Keywords}

affect, affirmation, negativity, relationality, vitalism, vulnerability

\section{Introduction: dancing with the abyss (Thomas Dekeyser)}

Engaging 'negativity' has never been a simple affair. Negativity annoys, horrifies, threatens, destabilises, or, simply, withdraws. And yet, asking himself what 'good literature' is, the writer Roberto Bolaño responded: 'the same thing it has always been: the ability to peer into the darkness, to leap into the void'. 'The greatest writers, he continues, are those entering the abyss with their eyes open, 'capable of dancing the conga with the abyss staring back at [them]'. ${ }^{2}$ For Bolaño, despite the dangers, the ability to embrace negativity - darkness, void, abyss - should be the marker of contemporary thought.

But how does one 'dance the conga' with negativity? A conceptual problem emerges: tracing negativity across the history of philosophy, we encounter vastly divergent interpretations. In Bolaño, negativity is the dark, impenetrable undercurrent propelling violence and suffering. In the eyes of Cioran and Schopenhauer, this negativity is the principle of existence, leading us into the destructive forces of life, both human and inhuman, in all its horror and fragility. Many centuries earlier, to the early Socratic philosophers, negativity presented a metaphysical and epistemological problem: that of non-being, and of negation as the development of thought. ${ }^{3}$ Taking inspiration from Plato's early dialectics, Hegel centred negativity as the driving force in the realisation of both Being and Ideas into greater forms. In his own reworking of Hegel's epistemological system, Theodor Adorno argues for a non-dialectical negativity, separating the moment of negation from any positive traits, from any final synthesis that would be greater than the sum of its parts. Along an altogether different conceptual path, 'negative theologists' in the Islamic and Christian traditions find in negativity the sole manner of approaching God, given that, in their view, God can only be known by that which can not be said about God, via negativa. Finally, within the black tradition, thinkers of 'afropessimism' 4 and 'black nihilism' have theorised negativity as the metaphysical violence of anti-blackness, and as the necessity for a politics 'in the place of the void' over one centred on hope.

These are but small fragments of philosophy's extensive dance with, and, at times, bewilderment by, the sway of negativity, but they do begin to show the conceptual incoherency of negativity across its various ontological, epistemological, political and affective registers. Staying within this inherent messiness and indefinability of negativity, the contributions in this paper, based on a panel discussion at the American Association of Geographers Annual Meeting in April 2021, were asked to reflect on the status of negativity in their work, and how they have responded to its pull and challenges. The contributors are brought together in this paper precisely for the diversity of their encounters with negativity. These encounters are led by distinct intellectual traditions (from Hegelian idealism to post-structuralist philosophies) and are probed by varying styles of writing (from first-person vignettes to theoretical reflections on a body of work). Rather than resolving these tensions, defining negativity narrowly or prioritising one style of writing, the paper showcases the diversity of work on negativity being undertaken by geographers and investigates how different perspectives may dismantle or expand particular tenets of geographical thought. Collectively, as we draw out in the Afterword, the reflections emphasise negativity as a geographical problem: it confronts us with the (im)possibility of relations between body and world.

To be sure, geographers have already, long before us, undertaken a fair bit of dancing with negativity. Having been associated initially to Marxist geographies in the shape of negative dialectics, ${ }^{6}$ one is now more likely to encounter it in the rich work on 'negative spaces' (voids, fissures, cracks, 
caves, holes), 'negative politics' (abolition, silence, withdrawal, refusal) and 'negative affects' (sadness, stillness, shame, weariness, indifference, incapacities to affect, inabilities to be affected, vulnerabilities). Negativity thus attunes us to the moments when bodies decay, fall ill, are traumatised, close down; when our grasp slips and we fail to engage with others, our exhaustion too cutting to muster the energy to keep going; when human and non-human spaces fall into disarray, slowly or abruptly or withdraw from human access; moments, in other words, when vitality and affirmation are impossible, unethical or undesirable.

But perhaps more than bringing new affects, spaces and politics into our disciplinary fold, negativity may, as contributors in this paper begin to show, beg us to reconsider some of the concepts at the very heart of geography. We could ask: how might we attend to ideas of 'space', 'world', 'affect', 'body', 'subjectivity', 'economy', 'politics' or, even, 'the field', if we begin not from the capacity to come together, to make-work, to build, as our discipline of 'earth-writing' and 'earthbuilding' often encourages us to do, but instead take seriously the imminent potential for crackingopen, falling apart, slowing down, encountering limits, becoming numb or coming to a stand-still? For instance, what happens to our ideas of life when we take not vitality, but fragility, destitution or quietude, as starting concepts, where negativity is literally a part of us, rather than something that happens to us? What would it mean to take politics and power as fraught with non-relations and incapacities? What might it mean to think of nonhuman environments as indifferent, rather than accommodating, to human life? What happens to our epistemologies and methodologies if we take seriously the unknowability and unthinkability of much of the world?

These are ambitious questions that require careful theorisation and empirical scrutiny. Beginning to think through some of these themes, geographers have engaged negativity as a manner to build on, or respond to, at least three influential theoretical impulses within the discipline. First, at times geographers have turned towards thinkers of negativity within a hesitation to embrace relational thinking within the discipline. Refusing to presume the possibility or sufficiency of relations, they turn towards the figures of 'non-relation', ' 'disconnection', "void'9 and 'failure'10 to account for those moments when the work of relations falls apart, fails to endure or could not be established in the first place. Second, geographers have begun to question, sometimes explicitly and other times less so, whether vitalist ontologies enable us to think through the sad passions, negative affects and diminished potential that mark contemporary life and how those might both enable and delimit our engagement with the world as people ${ }^{11}$ and as researchers. ${ }^{12}$ Finally, a number of geographers have sought to trace the limits of translating affirmation into a politics, ${ }^{13}$ ethics $^{14}$ and critique ${ }^{15}$ of generosity or enchantment, instead turning their attention to silence, ${ }^{16}$ stillness ${ }^{17}$ and refusal. ${ }^{18}$

Tracing and extending these threads, each contributor to this paper reflects on what negativity means to them. Through a comparison of two recent publications on negative geographies, Secor brings us into the necessity of 'negativity'. Without the negative 'nothing', she suggests in a Lacanian vein, no language, subjectivity or desire would ever attain a status of possibility. Rose encounters 'negativity' as the unsurpassable limit that underpins and undermines any claim to sovereignty, any willing. Taking negativity seriously, he argues, requires us to begin from the fundamental precariousness that marks the self. Starting from the commonplace critique of negativity as the flawed (Hegelian) move of transcendentalism, Bissell argues that, even within a metaphysics or politics of immanence, space needs to be made for limits. To do so, he shows us, we need to start from the confusing task that is the evaluation between joyful passions and sad passions, affects that open up and those that shut down. Zhang troubles the distinctions between 'good' and 'bad' feelings, productive and destructive negativity, in discussions of affirmation and critique. She argues that in emphasising the reparative potential of negativity, in arguing for a productive politics of negativity, we may run the danger of losing sight of the impassable vulnerability of existence. Romanillos offers careful reflections on the distinctions between 'negativity' and the terms 'the 
negative' and 'negation'. For him, negativity surges in different registers as a challenge to fixity: a force disrupting images of identity, as subjects' being-towards-death and as an epistemological refusal of canonical readings of theoretical texts.

Across these contributions, the paper explores negativity as the faltering, failure and impossibility of body-world relations that inevitably underpins our embodied realities, physical worlds and social lives. Doing so, it makes evident the stakes of venturing, alongside Roberto Bolaño, into a short, if precarious, dance with negativity.

\section{Speaking of nothing. .. (Anna Secor)}

What an awkward dance it is, this dance with negativity! First of all, I appear to be dancing alone, since my partner never did show up. But also, my movements are far from fluid: fits and starts, rhythmless twirling. This is not what you came for. But look again. All this movement, all these words - I won't say they are better than nothing, but they are everything to do with what recedes from them. In this short essay, I offer a perspective on the negative as that which is at once a precondition for movement (this dance, this speech, this apparent something) and for its failure, its incoherence. I will pursue this first by exploring the appearance of negativity in two recent books in geography. In the gap between them, I find the space to move the pieces of the puzzle of the negative around, to create some imperfect contribution to these reflections.

How extraordinary that not one but two books by geographers on the negative have been published this year. One of these, A Place More Void edited by Paul Kingsbury and myself, came out in February (2021) with University of Nebraska Press. The other one is Negative Geographies: Exploring the Politics of Limits, edited by David Bissell, Mitch Rose and Paul Harrison, also with University of Nebraska Press and also for publication in 2021. You might think that a book on the void and a book on the negative, both coming out in 2021 with the same press, could have been one book. But despite the considerable shared ground, including three shared authors, they are strikingly different books. This was exciting to me: the discovery of this difference, which speaks both to the diversity of the ways that negativity may be taken up in geography and to the paradox of the negative itself.

To summarise very briefly, Negative Geographies focuses especially on the limits of capacities and relations. In the preface, the editors suggest that they would like to offer a geography that is perhaps more humble and even more feeble. This is a project with profound ethical and political implications for the discipline: a step away from the overweening illusion of the masterful, autonomous and productive subject that still dominates the geographical enterprise. Negative Geographies picks at these ambitions, pulls loose their threads and undoes their seams. It does this with an unfolding of grief, suffering, submission and vulnerability - not as opportunities for repair or action, but as existential conditions of the world and the self. There is a stepping back from heroic claims to knowledge and understanding; instead, what pools around the reader is a sense of the limits of our capacities to know, to relate or to transform. Tarrying with the negative is one way to start making space for a different mode of geographical scholarship: One less bound to authority and extractive research practices. One more comfortable in the spaces of ambivalence, exhaustion and failure.

A Place More Void, though, is a horse of a different colour. In comparison to the introduction to Negative Geographies, which provides an erudite précis of the philosophical and political place of the negative for geography, the introduction to A Place More Void might seem a bit flip; it's playful, it gallops along. It begins from the premise that the void (dis)appears in many different ways, some of which may involve nonexistence while others may concern edges, absences, exclusions or holes. The purpose of A Place More Void - even beginning from the 2017 AAG sessions that began the plunge into the void - was to nurture this eclecticism. As indicated in the call for papers, the aim 
was to bring as many different voids we could together: silences, caves, wounds, abysses, sites of urban demolition, vortexes, supernatural beings, archival erasures, political impasses. After all, the void is no(one)thing. A Place More Void attempts to stage an encounter with the void in geography, while acknowledging (demonstrating perhaps) that the void is a notorious no-show.

There is a tension between A Place More Void's rather eager wager that there's a lot you can do with nothing and what one might more likely derive from Negative Geographies: that there is nothing to 'do' with nothing, and in fact it is the doing itself that is suspect. The non-correspondence of these twin books thus traces the dimensionless edge of reversal between antinomies, wherein nothing has a tendency to reverse into something (without any collapse between the two). In other words, instead of subsuming, overlaying or negating one another, the two books sit alongside one another in a kind of amiable silence. Or maybe this resting together is not so silent. I think perhaps A Place More Void is chattering rather incessantly, whilst Negative Geographies withdraws. Anyhow, it's a non-relation that works for them, a failure to communicate that is the essence of whatever they are able to say.

In fact, it is not the appearance of these two books but the parallax between them that, in my view, bespeaks the negative. For at the same time as there is nothing to do with nothing, one might also say that one can't do without it. This is a principle of Lacanian thought. Without a first exclusion or loss, nothing else can come into being; the subject needs to be cut off and set adrift (from the mother, from the desire of the Other) in order to enter into the play of desire and language. In language, this loss or exclusion takes the form of the missing signifier - that is, the non-correspondence between the chain of signifiers and signifieds, such that one always says more and less than one means - that allows for the play of signification.

From this perspective, language and subjectivity are premised on the 'empty square'. The recurring image that I have in my head - what helps me to 'get' the requirement for negativity on a visceral level - is of a sliding tile puzzle: a square frame holding 15 smaller square pieces that can be moved around to form a picture or a sequence. The essence of the puzzle is the gap, the missing square. None of the squares would be able to move if the whole thing were full, if there were no empty place. Without the gap, the grid would be locked down, every square in immutable correspondence with its place. The empty spot is what initiates the play: it allows the squares to move, to be rearranged so that one can create an image that 'makes sense' (as per the ideal order predetermined by the puzzle-maker). The possibility of movement is what allows both the play and for there to be a difference between the ordered image and all the permutations of disordered ones. Further, the picture once composed is always incomplete: the only image possible is one that includes a blank spot. The empty square is not part of the picture (in fact it is a 'stain' in the picture, the place where the picture is not) but it is what makes any picture (or non-picture) possible.

Negativity is difficult to speak of, and I suspect I have failed. I think of one of Lacan's enigmatic statements: 'I ask you to refuse me my offering, because this isn't it' ${ }^{19}$ In other words, whatever it is that I offer to you, it is not the thing that you seek. And it is also not the thing that I am giving. It is, in a sense, in its place. I offer these words, not because they are what I longed to say to you, or what you longed to hear, but because they are what there is instead of that. Only if you refuse this proffered relation, refuse these words - only if you recognise that this is not what I came here for, that I have not delivered what you asked from me, that what I said is all in the gaps (is all unsaid) - only then may we inhabit the (non)relation that occupies the space between us.

\section{Negativity as limits (Mitch Rose)}

When Thomas Dekeyser first proposed this session, he asked us to consider those modes of negativity that have been most influential in our work. While of course I've been influenced by an array 
of thinkers, my work has probably been most affected by the writings of Emmanuel Levinas and particularly his concept of subjectivity. Specifically, the idea that subjectivity is fundamentally precarious. His takeaway point from the horrors of the Second World War is that human existence is not anchored in a will, our minds, our rights, our freedoms, our individual capacities, etc., but rather is dependent on others. Other people, to be sure, but also a wide realm of other conditions: food, sunlight, warmth and language. This seems to be something we've kind of forgotten in our secular post-Boomer world. While my parent's generation often frame dying as a failure (something that happens because the doctor didn't save you), I am constantly amazed that my heart beats (on its own!) and has done so for 52 years. And while its eventual failure will be something I resist (and no doubt agonise over), I don't think I'll be surprised. I have no say over my heart. It's mine but it's not mine. Even though it keeps me alive, it is fundamentally outside of me. I take care of it but it doesn't owe me anything for that care. There's no transaction here. It is not attentive or responsive to my will - it doesn't make deals. ${ }^{20}$

While I, like others, have been very invigorated by the work of JD Dewsbury, David Bissell, Derek McCormack who write about the body's capacities and plasticity, I don't think - and David Bissell would agree with me on this - that we've paid enough attention to the vulnerability of bodies. By this I mean, we have not attended to how bodies are susceptible to the world outside us, not simply because bodies are reliant on what the world gives (though obviously they are), but because we have no say over that gift or its giving. These are things we can't touch, cannot claim, cannot possess as ours. So this is the encounter with the negative that I've been circling around: negativity as a limit, as a threshold we cannot cross. A boundary that's not simply another obstacle to be overcome, transgressed or transcended, but a limit that perpetually undermines any and every willing, that erodes every claim to sovereignty, to be what Heidegger called a 'self-standing being' or an 'own self'. ${ }^{21}$

To finish off, I want to reflect on whether our current global predicament will precipitate any kind of shift towards the negative in the discipline. Will geographers write about the new capacities that have emerged from being in lockdown, the undiscovered aspects that have blossomed from a year of corporeal retreat? Or will it lead to a reckoning, a search for frameworks that do something besides celebrate our potential, our infinite capacity for connection and affirmation?

I pose this question because I, probably like many of you, lost someone this year. The last of my grandparents died from the disease early on. Unable to travel and mourn with family intensified the sense of helplessness. While I watched the funeral via live stream, I couldn't help but wonder what all my grandparents would have made about the pandemic. Would they be surprised? These people who reminded me all the time of life's precarity? Who told me that I was one generation and a boat ride away from death and that everything I took for granted about my life, my body, my future and my world, could be gone in a second? Geologists have long recognised that the Holocene (the period in which most human history has evolved) has been one long lucky accident, providing a relatively stable climatic world with no mass extinction events like the one we're experiencing now. When did we come to see this world primarily in terms of its availability? As if its energies and elements were all set up before us awaiting our appropriation? My grandparents did not see themselves as agents. Even as they skilfully evaded the dark fogs of violence that threatened to engulf them, they always remembered their limits; the happenstance and timing they could not calculate but was often the difference between living and dying. My grandma (the one who passed away) always complained. She complained about my dad, the portion sizes, the service, the neighbourhood, the blacks, the pain, the boredom, the nurses, the list goes on. But when I saw her last, she said that this would be the last time. I said, 'no, Grandma, you're tough. You're a survivor'. And she said, 'no, I've just been lucky'. 


\section{Confused evaluations (David Bissell)}

The negative is an open question for geographers. Yet it's curious that recent affirmative critiques have tended to defer to a specific understanding of the negative articulated by Deleuze who roundly condemns it as 'only the shadow cast upon the affirmations produced by a problem: negation appears alongside affirmation like a powerless double, albeit one which testifies to the existence of another power, that of the effective and persistent problem'. ${ }^{22}$ This acerbic evaluation of the negative responds to Hegel's dialectical negativity - where the pursuit of truth proceeds through negating other, misplaced ideas: a dialectics expressed through the critical tradition in geography where dominant meanings are contested to destabilise entrenched powers. Affirmative critique is suspicious of dialectical negativity owing to its transcendent framework which is fundamentally at odds with philosophers of immanence, especially the Spinozist affirmative metaphysics that so enamoured Deleuze. The problem with this way of conceiving the negative for thinkers of immanence is ontological separation, holding onto the notion of finite things. From a Spinozist perspective, such ontological separation is simply false, premised on a politics of recognition that forgets how all finite modes are derived from the infinite nature of God.

I admit that I'm still seduced by the lures of non-organic vitalism. Exposure to the 'vital force of difference ${ }^{23}$ means that there is always more in this shimmering world - who wouldn't be entranced by this promise for critical politics? Our habits of prioritising molar imaginations of finite beings can certainly risk overlooking vital ongoing molecular differentiation that takes place through different forms of expression. And yet there is an outside, a negative, that still seems to insist, for me at least. Much of my own thinking has been concerned with diminished capacities to act and feel: pain, exhaustion, ingresses that reduce a body's capacities to affect and be affected. And this invites a different negative - not a Hegelian dialectical negative that transacts, but an irresolvable negative that admits limits. For post-phenomenological thinkers of immanence, such concerns still likely represent a misguided obsession with finite organic beings. Roberts and Dewsbury, ${ }^{24}$ for example, reject what they call a phenomenological 'micro-geographical' approach to thinking difference through the straightjacket of recognition, presenting us with a fundamental choice: either phenomenological transcendence or post-phenomenological immanence. And they stress that this is our choice to make. My choice is that we must make space for finitude - for limits - within affirmationism, even when guided by a politics of immanence. For me, this choice involves deepening our appreciation of how bodies process passive affects.

For Spinoza, bodies are always undergoing change through the encounters that they have. Bodies are 'in a constant state of de- and re-composition in relation to other bodies, even in the most mundane acts of everyday repetition' ${ }^{25}$ Deleuze particularly admires the practical, collaborative dimension of Spinoza's Ethics, concerned with how increasing powers of acting requires us to encounter other bodies, human and non-human. To gloss all too quickly what Deleuze draws from Spinoza, the nub of this practice - coming into possession of one's power - involves turning passive affections into active affections, and to develop common notions through the formation of awareness of causes. ${ }^{26}$ This is a seductive promise. But the problem is that such didacticism is premised on a fundamental capacity to immanently evaluate between joy and sadness; between an increase or decrease in one's powers; between opening up and closing down; between positive becoming and negative regress. What if, as many geographers' work suggests, this is simply not the case?

Curiously, the non-relational remains crucial for thinkers of immanence where cuts, tears and limit experiences are integral dimensions of transformation. Rather than thinking about absolute human finitude, Deleuze ${ }^{27}$ himself invites consideration of a more inhuman notion of finitude, which moves beyond thinking exposure as potentially traumatic infraction, towards imagining how 
exposure is the necessary site of passivity to activate a change in state - a modification to a body, an affect. This is a primary exposure to a 'non-representational voice from an always differentiating and non-relational elsewhere'. ${ }^{28}$ Rather than prioritising relations, there is a much more ambivalent orientation towards relationality for Deleuze, where experiences that disrupt 'the everyday world of connectedness and disturb the functioning of the sensory motor apparatus are valorised, but the hoped-for consequence of the destruction of everyday relations is a connectedness to the cosmos'. ${ }^{29}$ The ambivalent operation of finitude is present in Deleuze's writing on Nietzsche where he rethinks the conventional hierarchy of active and reactive forces. On one hand, where an active force is 'one which goes to the limit of its consequences', ${ }^{30}$ experiences of limitation such as exhaustion could be imagined as a reactive force - a force that separates a body from what it can do. But Deleuze asks whether we could think of such experiences as reactive forces becoming active: 'does not this reactive force, in its own way, go to the limit of what it can do?' ${ }^{31}$ Deleuze offers the example of illness, writing how illness "narrows my possibilities and condemns me to a diminished milieu to which I can do no more than adapt myself' ${ }^{32}$ However, he suggests that 'in another way, it reveals to me a new capacity, it endows me with a new will that I can make my own, going to the limit of a strange power'. ${ }^{33}$ Something like illness might then 'bring us new feelings and teach us new ways of being affected'. ${ }^{34}$

However, incorporating limits into a Spinozist immanent schema of becoming denies the crushing reality of limits as limits. What at first blush appears to be a privileging of the non-relational for Deleuze is ultimately restored to a higher-level relationality. ${ }^{35}$ Though Spinoza provides a guiding ethos for living, this is not what happens in a world filled with confused thought. ${ }^{36}$ Indeed, Spinoza admits that becoming active is actually a rather rare accomplishment, since we are mostly dominated by our passions - our passive affects - and confused ideas. Since our social worlds are made up of beings whose powers of understanding are necessarily limited, it is this politics of evaluation that interests me most. ${ }^{37}$ Evaluation of passive affects is a complex and confusing business - something even the most ardent Spinozists agree on. As Hardt says, '[ $t$ ]he power to be affected as we really are (not as some people wish us to be) is filled with affects that are complex and contradictory. The field of the affects often looks like a briar patch, impassable and sometimes a minefield'. ${ }^{38}$ Yet such evaluations are not transcendental stepping outside and looking in, but ongoing modes of living. As Deleuze himself writes, '[e]valuations, in essence, are not values but ways of being. . . This is why we always have the beliefs, feelings and thoughts that we deserve given our way of being or our style of life'. ${ }^{39}$ So, though we might wish to join Nietzsche's affirmation even of what depletes us, there's a fine evaluative line between being productively disturbed and being mercilessly traumatised, and this evaluation itself seems to quiver. Ultimately, I agree with Hardt ${ }^{40}$ that 'political projects are not only (and not even primarily) a matter of reason and interests but instead an engagement with our power to be affected in all its messiness and, sometimes, its ugliness'. This demands a sustained attention to bodily evaluations of passive affects.

\section{The permissibility of bad feelings (Vickie Zhang)}

It's 2018, and I'm in a small city in China. Although I'm trying to concentrate on the task ahead, I can't seem to settle my thoughts and feelings. Instead, I am losing control over my body. Weeks into fieldwork and five thousand miles from home, I find myself becoming fragile, resentful, selfabsorbed. I feel introspective, irritable and, frankly, unwell. In the midst of an intensifying spiral, my body becomes a resonance chamber for ugly feelings; relations become replaced by deep senses of non-relation to the people and places around me.

At the time - at least to me - the atmosphere of cultural geography felt oppressively affirmative: about joy, play, care and connection with the figures and scenes that one inhabited for work and 
study. As geographers have noted, a set of aligned approaches have been proliferating across the discipline. Grouped broadly under the category of 'affirmationism', these diverse approaches often, implicitly or explicitly, relate the productive and creative potential of geographical practice to the work of feel-good affects. As Dekeyser and Jellis put it, affirmationism is 'the inclination to embrace . . . the productive forces of inciting, sustaining and cultivating existence'. ${ }^{41}$ It emphasises modes of inquiry that 'disclose possibility', ${ }^{42}$ attuning to and enacting the potentials for difference and becoming always available in an inexhaustible world.

In 2018, however, I didn't feel those happy intensities. I try, but I can't. Unable to reconcile these 'affirmative' demands with the less-than-affirmative reality of how I actually feel, I become overwhelmed by a confusing dissonance. Inspired by post-colonial practices of embodied writing, ${ }^{43} \mathrm{I}$ begin to write in an attempt to work through these feelings. Working through a series of back-tracing vignettes, I find myself unexpectedly exploring my conflicted relationship to my Chinese heritage, as an Australian-born geographer working on China. This writing eventually, painfully, becomes an essay reflecting on the difficult demands of my work as a diasporic 'translator', linking this dissonant feeling space to questions of affirmation and critique being raised in geography more broadly. ${ }^{44}$

It is true, upon closer analysis, that affirmation and critique cannot easily be mapped onto specific states of feeling. Ruez and Cockayne carefully explain that 'affirmation' is not just about 'feeling good'; each constitutes a distinct style of approach and the two should not be conflated. ${ }^{45}$ This is a point that Ahmed also makes in her discussions of happiness and affirmation, recognising that (perhaps confusingly) 'good feelings aren't necessarily about feeling good' ${ }^{46}$ Both agree, however, that there has nonetheless been a strong tendency to merge the two approaches, with researchers consistently combining affirmation with feeling good - and, on the flipside, critique with feeling bad - resulting in 'the risk of an implicit connection between the two' ${ }^{47}$ Understanding the 'affirmative turn as belonging within the same horizon as the happiness turn', ${ }^{48}$ Ahmed suggests that this tendency can be further linked to a wider tendency in western thought to align 'positivity' with activity, happiness, joy, life and good feelings and 'negativity' with passivity, ressentiment, sorrow, death and bad feelings.

Noting, then, that affirmation is not just about feeling good and critique is not just about feeling bad, given these enduring resonances I want to continue aligning these stances for diagnostic reasons. Unable to access the affirmative disposition I believed was necessary, I spent 2018 feeling like a geography 'affect alien': alienated by my failure to 'desire in the right way', by how I was affected by the world and by my inability to take joy in my objects of interest. ${ }^{49}$ Although this failure did not (and still does not) feel like the fault of the neoliberal university, as in Davies, Disney and Harrowell's diagnoses (at least not in any straightforward way), it was nonetheless conditioned by the expectations I felt placed upon me - and I placed upon myself - as an academic geographer. ${ }^{50}$ As failure, it was not one that stemmed from an act of neglect or the receipt of a rejection, as in Turner's analysis, but from the recognition of a more passive failure to feel the right way: to embody the interested, enthralled and affirmative subjectivity I imagined as necessary to research. ${ }^{51}$ In this sense, affirmation's injunction to feel-good forms of relation alienated me, intersecting with an already-fragile self in ways that overwhelmed me further. I felt like an impostor, an outcast and a liar-by-omission for not being able to feel how I felt I should feel.

For a variety of reasons, things feel a bit different in 2021. As previously alluded to, recent critiques of affirmation have worked to deconstruct negative feeling-spaces by questioning how apparatuses of knowing become mobilised in the wake of feeling events. Geographers are increasingly rejecting the affirmative dismissal of critique in favour of the situated work of such responses, advocating ethoses of ambivalence, undecidability and hesitation. ${ }^{52}$ In these approaches, the value of feeling itself is ambivalent: what matters is not good or bad feeling, but what these situated 
forms of feeling can $d o$, involving 'strategic and local decision[s]' that recognise the local and historical ecologies in which diverse forms of action and reaction take place. ${ }^{53}$ Scholars are working to reclaim negative feelings, valuing not their valence but their capacity to generate an affirmable 'politics of difference', ${ }^{54}$ with depression, unhappiness, failure and weariness each acting as a 'possible resource for political action' and transformation. ${ }^{55}$ In this way, geographers are rightly 'push[ing] the boundaries of what [it] is deemed acceptable to feel and embody in academia'. ${ }^{56}$

But although I empathise with this vital desire to revalue negativity, something about this drive to repair bad feelings sits uncomfortably with me. It seems that bad feelings are still only being acknowledged for the productive projects they are able to inaugurate - adding a wider range of affects to the scope of affirmable action, but not fundamentally changing its 'positive' and productive impulse. ${ }^{57}$ There are fundamental tensions between the future-anterior orientation of this revaluation of negativity (tethered to the possibility of a future moment of repair) and the related suggestions to stay suspended in the open temporality of the 'impasse' (working and waiting, perhaps, for the affirmable moment to arise). The problem is not just academic. In Sedgwick's formulation, drawing on Melanie Klein, it is not easy to move from the paranoid/schizoid (critical) position to the reparative/depressive (affirmative) one. It 'represents an actual achievement' to move towards affirmation, involving an emotionally fraught, difficult and deeply personal experimentation with the self. ${ }^{58}$ Inhabiting an impasse is 'sweaty' and 'uncomfortable' embodied work, in ways that no words can do justice to. ${ }^{59}$ And as Bissell suggests above, undertaking this work shouldn't come without hesitations and difficult evaluations: there are very real reasons why one might not wish to go down the path of confronting conflicted feelings, including the fact that there are no guarantees of a 'good' or reparative outcome.

Affirmations of ambivalence in geography are offered in the hope of opening up the politics of choice, 'resist[ing] singular prescriptions of positive or negative affect' in ways that better align with the situated work of political projects. ${ }^{60}$ Whilst it would be ideal to live in a world where we can curate our feelings for their political potential, the affirmative drive to repair bad feelings still seems, at times, to put the cart before the horse. This is as much about how we narrate the potential of others' feelings, as it is about the difficulties of inhabiting our own; it is about the incomparable choices we all must make in the often-blurred spaces of life and work. What should those of us already swept up in the depths of feeling do with these uncertain promises of repair? In 2018, I didn't get to prescribe my bad feelings; they chose me. Bad feeling is not a reserve of potential waiting to be redeployed, nor is it exhausted by the reparative project it might - and only might become. Its negativity is in its impotentiality, in the humility of its limits, in the vulnerability of human existence. ${ }^{61}$ As Harrison writes, citing Hans-Pile, 'while you may exceed to a state of amor fati in relation to your own wounds, it does not follow that you should love the harms that others undergo, or the powerlessness you may feel in the face of their harms' ${ }^{62}$ Thinking back to 2018 when I was trapped in the midst of bad feeling, what I needed to hear was not that these feelings would or could or should be repaired, affirmed or re-ascribed value; what I really needed to hear was that it was okay to feel this way, that there was nothing I needed to do with those unaffirmable feelings, and that, in an irresolvably less-than-ideal world, it was not my fault that those feelings were mine.

\section{Negativity, the negative and negation (José Luis Romanillos)}

In being asked to respond to the place of negativity in my own work, I struggled to pinpoint where it has been explicitly addressed. I realised instead that the place of negativity was in fact dispersed through a constellation of related topics such as death, absence, finitude, nihilism, exposure, 
vulnerability and so on. ${ }^{63}$ At the same time, it seemed that the idea of addressing negativity would also require consideration of two very closely related notions: 'the negative' and 'negation'.

As Dekeyser and Jellis suggest, ${ }^{64}$ there are a number of taken for granted associations with respect to negativity, including the presumption of its oppositional character with respect to active, life-affirming notions of vitalism. This can be drawn out with respect to the negative, which is indeed difficult not to understand in terms of an oppositional character. For example, the negative is like one end of a pole, representing darkness, limits, dissolution or passivity and it stands against the day-light, exuberance and creative action of 'the positive'. This oppositional appearance in turn can colour the perception of 'negativity' more broadly, such that we find a polarity of negative/ positive, negativity/positivity. Such an oppositional quality persists even when it is not obvious that negativity actually stands opposed to a sort of 'get up and go' positivity which Dekeyser and Jellis discuss in terms of 'affirmationism'.

This situation can also be drawn out if we take the case of 'negation', for negation is certainly not an oppositional notion or category, coloured by its conceptual distance from something positive. Rather, it is a speculative or contradictory notion, for here we find a concept intimately aligned with negativity that is in fact precisely a positive act, an action that is carried out by a subject, at least as regards its use in Hegelian thought. In response to an obdurate external world, a real which resists, human action negates what is there and in so doing creates its own spiritual or cultural domain - raising itself by its own boot-straps, so to speak. In this sense, the path of negativity does not lead to some otherworldly place or lugubrious crypt from which action, projects or goals are dissolved in exhaustion, but places us squarely amidst all manner of affirmationist activity, beings and forces. When Bataille wished to challenge the structure of Hegelian thought, by means of an expression of purposelessness or uselessness, he wrote in a letter to Alexandre Kojève that he was a 'negativity with nothing to do'. ${ }^{65}$

In terms of my own work, I have probably drawn upon notions of negativity in three main ways. Firstly, I've used it as a means of thinking about human action, subjectivity and conceptualisations of the world. Negativity here in fact aligns with other 'processual' conceptions of subjectivity, as it also challenges fixed and static images of identity. In the work of Jean-Luc Nancy, ${ }^{66}$ for example, it is the restlessness of the negative which underscores human action in terms of a perpetual breaking of limits.

Secondly, I've used it in terms of a broader set of theorisations around conceptualising mortality, death and finitude. I don't want to replace one conceptually dense term with another - but finitude is probably the most extensive approach I have taken with respect to 'negativity' more broadly, drawing upon the work of Heidegger and his famous existential analytic of being-towardsdeath. The perspective I have taken is that there are all manner of implicit and explicit spatialisations of this existential relationship that are worth considering.

Lastly, apart from enabling a study into the differential ways in which humans are exposed to death, I have also considered negativity and finitude as important paths for understanding epistemological positions in geographical knowledge. It is with respect to this last, epistemological use of negativity that I will end, for it represents part of what I have been doing over the last few years on a book project titled What is geophilosophy? The aim is to develop a Hegelian reading of the history and philosophy of geography - one which places conceptualisations drawn from a philosophy of negation and negativity centre stage for making sense of the development of geographical thought. As I've mentioned, in Hegelian philosophy, negation appears as a speculative or contradictory concept, woven into the wider fabric of his thought. I think that what is significant about it, geographically speaking, is that the speculative has perhaps not been given the time of day in terms of thinking through the geographical corpus - an archive that has tended to be read, interpreted and taught in terms of the architecture of Kant, the archaeology of Foucault, the materialism of Marx 
and in fact with all manner of explicit warnings about using Hegelian thought. But to reconsider these familiar warnings is to recognise that Hegel has been the subject of a number of distortions, so ingrained that they amount to veritable theoretical catechisms of the self-evident. These include, for example, the idea that approaching Hegel is fine, just as long as one handles him with Marxist gloves; that one begins and ends with the conclusion that Marx 'materialises' Hegel; that Hegel is all about 'dialectics'; that Hegelian thought represents an idealism analogous to Kant, one that we must strive to surmount; and that nothing is more despicable or embarrassing than teleology. But to avoid such a reading of Hegel is to open the question as to what Hegelian thought might offer to investigations of the history and philosophy of geography. It is to remember the lesson of Derrida that texts remain to be read. Negativity, in this sense, might allow us to look awry at familiar content, and in so doing, reveal the strange persistence of apparently self-evident theoretical readings and methodological norms.

\section{Afterword (Thomas Dekeyser and David Bissell)}

We begin this final section with a return to the paradoxical image with which this paper started: dancing the conga with negativity. It is no accident that we are drawn to this strange figuration. For a generation of cultural geographers interested in non-representational theory, dance has served as one of the most potent expressive lures to think about a body's relations with its environment. As a bodily practice, it overbrims with positive potentials - positive in the sense of the presence of forces, materialities and landscapes. Dance has been a portal through which to explore the micropolitical changes in capacities to affect and be affected that happen when bodies enter into relation with other bodies, affects, materialities and rhythms. ${ }^{67}$ Dance brims with potential for liberation, working as a 'catalyst of transition' ${ }^{68}$ If dance is a way of thinking body-world connections, how on earth does one dance with something so inexpressible, so unsurmountable, as negativity? The room darkens, the music goes mute, the bodies still. This is no longer the dance of joyful expression, of bodily intertwinement or of rhythmic attunement to the more-than-human. Instead, it is perhaps a dance of utter exposure to the world.

In their own way, and through different theoretical interlocutors, each contributor reflected on this recurring theme: negativity as the (im)possibility of relations between body and world. Leaning on Lacanian thought that insists that desire and language emerge owing to the bodily experience of being cut off and set adrift, Secor emphasises that nothing can emerge without these primary gaps, absences and losses. Levinas's thought provides a way for Rose to foreground the fundamental bodily vulnerability that comes from being exposed to others over which we have no control. Deleuze's strange negatives are Bissell's starting point for considering diminished capacities to sense and act in the world, flagging the bodily incapacities for evaluating such modulations. Sitting in the background of her text, Ahmed is Zhang's key interlocutor, allowing her to remain in an ambivalent space of bad feelings whilst refusing to reconnect to the promise of a more ideal world. Nancy, Heidegger and Hegel provide inspirations for Romanillos who foregrounds a more processual understanding of negativity that is concerned with the breaking of limits and being towards death. Though many of these theorists have been mobilised in geography to advance relational understandings of bodies and worlds, in this context, we are confronted with the difficulties and impossibilities of relations: a dance with no handholds.

The authors have reflected on the usefulness of negativity, and the many related concepts and traditions it engenders, in helping them encounter, write and think this problem of 'non-relations'. The discussed concepts offer geographers a series of challenges and triggers for thinking through those moments - brief or extensive, mild or intense, necessary or accidental - when body-world engagements slip, fade out, shatter, darken or fail to emerge in the first place and how such moments may come to trouble how we approach understandings of 'space', 'affect' and 'politics'. But, as 
some contributors suggested, the non-relational can never be taken for granted. Its connection to the 'relational' is complex and at times fraught. Non-relations can at times, as Secor and Romanillos have shown in this paper, place us amidst affirmation, becoming a necessary cornerstone in the building of relations. Further complicating any straightforward attendance to the non-relational is its tendency to withdraw. We can never empirically grasp, let alone fully know, the degree and extent of the non-relation without subordinating it to an act of affirmation. ${ }^{69}$ Together, the contributors have therefore worked against a dichotomous choice between non-relation and relation, negativity and positivity, negativity and affirmation or even a dialectical resolution of such poles, and instead, opt for a refusal to settle tensions. However, they do so whilst indicating that even within a posthumanist politics, we still have choices to make that we must take responsibility for.

Negativity, then, poses a series of questions to which there are no clean answers. Answers will likely not be found in a simple disavowal of 'older' turns in geographical thought. In responding to the provocation of negativity, we do not argue for a novel 'sub-discipline' of negative geographies. Indeed, we eschew simplistic labellings of 'old' or 'new' traditions or theorists. Instead, as some contributors have indicated, negativity evokes a modest wariness of dogmatism, both in terms of which thinkers, texts and methods to turn to and how exactly one might do so. We may well wish to familiarise ourselves with intellectual terrains largely unknown to cultural geographers, or decide to re-read and counter-read familiar thinkers and texts. There are, for instance, aberrant Deleuzes, Lacans, Hegels and Heideggers to be read, alternative humanisms and post-humanisms to encounter and discordant writing styles to pick up, rework or disfigure. But perhaps all this is too demanding, a betrayal of negativity, as if it is yet another invitation for more, more, more. In fact, negativity leaves us with little to hang on to, little to hope or long for, even as it gives us something to do along the way.

\section{Acknowledgements}

We want to thank the audience members at the AAG Annual Meeting 2021 conference session on which this paper is based for their insightful comments and questions. In addition, we would like to thank Dydia Delyser for her expert editorial guidance and the two editorial reviewers for their helpful comments.

\section{Funding}

The author(s) disclosed receipt of the following financial support for the research, authorship, and/or publication of this article: Thomas Dekeyser is supported by a British Academy Postdoctoral Fellowship (award number: PF19_100052).

\section{ORCID iDs}

Thomas Dekeyser (iD https://orcid.org/0000-0002-3809-313X

Vickie Zhang (iD) https://orcid.org/0000-0002-3368-1522

\section{Notes}

1. R.Bolaño, Between Parentheses (London: Picador, 2016), p. 34.

2. Bolaño, Between Parentheses, p. 222.

3. R.Brassier, 'That Which is Not: Philosophy and Entwinement of Truth and Negativity', Stasis, 1(1), 2013, pp. 174-86.

4. F.Wilderson, Afropessimism (New York: Liveright Publishing, 2021); J.Sexton, Amalgamation Schemes: Antiblackness and the Critique of Multiracialism (Minneapolis: University of Minnesota Press, 2008).

5. C.Warren, 'Black Nihilism and the Politics of Hope', CR: The New Centennial Review, 15(1), 2015, p. 234.

6. N.Castree, 'Birds, Mice and Geography: Marxisms and Dialectics', Transactions of the Institute of British Geographers, 21, 1996, pp. 342-62; G.Mann, 'A Negative Geography of Necessity', Antipode, 40, 2008, pp. 921-34. 
7. P.Harrison, “"How Shall I Say it ... ?" Relating the Nonrelational', Environment and Planning A: Economy and Space, 39(3), 2007, pp. 590-608; V.Zhang, 'Ethics for the Unaffirmable: The Hesitant Love of a Cultural Translator', in D.Bissell, M.Rose and P.Harrison (eds), Negative Geographies: Exploring the Politics of Limits (Lincoln: University of Nebraska Press, 2021), pp. 92-128.

8. D.Bissell, E.R.Straughan and A.Gorman-Murray, 'Losing Touch With People and Place: Labor Mobilities, Desensitized Bodies, Disconnected Lives', Annals of the American Association of Geographers, 110, 2020, pp. 1891-906.

9. P.Kingsbury and A.Secor (eds), A Place More Void (Lincoln: University of Nebraska Press, 2021).

10. B.Anderson, 'Failures of Interest', Emotion, Space and Society, 35, 2020, pp. 1-4.

11. S.Brice, 'Geographies of Vulnerability: Mapping Transindividual Geometries of Identity and Resistance', Transactions of the Institute of British Geographers, 45(3), 2020, pp. 664-77; P.Harrison, 'Corporeal Remains: Vulnerability, Proximity, and Living on After the End of the World', Environment and Planning A: Economy and Space, 40(2), 2008, pp. 423-45; P.Harrison, 'After Affirmation, or, Being a Loser: On Vitalism, Sacrifice, and Cinders', GeoHumanities, 1(2), 2015, pp. 285-306; E.Hitchen, 'The Affective Life of Austerity: Uncanny Atmospheres and Paranoid Temporalities', Social \& Cultural Geography, 22(3), 2021, pp. 295-318; C.Philo, 'Less-Than-Human Geographies', Political Geography, 60, 2017, pp. 256-8; R.Raynor, '(De)composing Habit in Theatre-as-Method', GeoHumanities, 3, 2017, pp. 10821; J.L.Romanillos, 'Mortal Questions: Geographies on the Other Side of Life', Progress in Human Geography, 39, 2015, pp. 560-79; M.Rose, 'Envisioning the Future: Ontology, Time and the Politics of the Nonrepresentation', in B.Anderson and P.Harrison (eds), Taking-Place: Non-Representational Theories and Geography (Farnham: Ashgate, 2010), pp. 341-61; E.R.Straughan, D.Bissell and A.Gorman-Murray, 'Exhausting Rhythms: The Intimate Geopolitics of Resource Extraction', cultural geographies, 27, 2020, pp. 201-16; E.Wilkinson and I.Ortega-Alcázar, 'The Right to be Weary? Endurance and Exhaustion in Austere Times', Transactions of the Institute of British Geographers, 44(1), 2019, pp. 155-67.

12. How failure plays out within the neoliberal university (as a site of fieldwork, teaching, and administration) was the concern of a recent Special Issue in Emotion, Space and Society. See for instance: T.Davies, T.Disney and E.Harrowell, 'Reclaiming Failure in Geography: Academic Honesty in a Neoliberal World', Emotion, Space and Society, 38, 2021, pp. 1-7; J.Horton, 'Failure Failure Failure Failure Failure Failure: Six Types of Failure Within the Neoliberal Academy', Emotion, Space and Society, 35, 2020, pp. 1-6; A.Broeckerhoff and M.M.Lopes, 'Finding Comfort in Discomfort: How Two Cross-Disciplinary Early-Career Researchers are Learning to Embrace 'Failure", Emotion, Space and Society, 35, 2020, pp. 1-4; C.Oliver, 'Beyond-Human Research: Negotiating Silence, Anger \& Failure in Multispecies Worlds', Emotion, Space and Society, 35, 2020, pp. 1-4; R.Whittle, L.Brewster, W.Medd, H.Simmons, R.Young and E.Graham, 'The 'Present-Tense' Experience of Failure in the University: Reflections From an Action Research Project', Emotion, Space and Society, 37, 2020, pp. 1-12.

13. K.Macfarlane, 'A Thousand CEOs: Relational Thought, Processual Space, and Deleuzian Ontology in Human Geography and Strategic Management', Progress in Human Geography, 41, 2017, pp. 299-320.

14. Harrison, 'After Affirmation'.

15. D.Ruez and D.Cockayne, 'Feeling Otherwise: Ambivalent Affects and the Politics of Critique in Geography', Dialogues in Human Geography, 11(1), 2021, pp. 88-107.

16. A.Kanngieser and N.Beuret, 'Refusing the World: Silence, Commoning, and the Anthropocene', South Atlantic Quarterly, 116(2), 2017, pp. 363-80.

17. P.Harrison, 'The Broken Thread: On Being Still', in D.Bissell and G.Fuller (eds), Stillness in a Mobile World (London: Routledge, 2011), pp. 209-28.

18. T.Dekeyser and T.Jellis, 'Besides Affirmationism? On Geography and Negativity', Area, 53(2), 2021, pp. 318-25.

19. J.Lacan, . . Or Worse. The Seminar of Jacques Lacan, Book XIX (Cambridge: Polity Press, 2018), p. 70.

20. J.Derrida, On Touching: Jean-Luc Nancy (Stanford: Stanford University Press, 2005).

21. M.Heidegger, Being and Time (New York: Harper, 1962).

22. G.Deleuze, Difference and Repetition (New York: Columbia, 1994), p. 267. 
23. T.Roberts and J.D.Dewsbury, 'Vital Aspirations for Geography in an Era of Negativity: Valuing Life Differently With Deleuze', Progress in Human Geography. Epub ahead of print 1 March 2021, p. 9. DOI: $10.1177 / 0309132521996462$.

24. Roberts and Dewsbury, 'Vital Aspirations'.

25. S.Ruddick, 'The Politics of Affect: Spinoza in the Work of Negri and Deleuze', Theory, Culture \& Society, 27, 2010, p. 28.

26. See T.Roberts, 'In Pursuit of Necessary Joys: Deleuze, Spinoza, and the Ethics of Becoming Active', GeoHumanities, 5, 2019, pp. 124-38.

27. G.Deleuze, The Logic of Sense (London: Continuum, 2004).

28. J.D.Dewsbury, 'The Singularity of the 'Still': 'Never Suspend the Question", in D.Bissell and G.Fuller (eds), Stillness in a Mobile World (London: Routledge, 2011), p. 181.

29. C.Colebrook, 'A Cut in Relationality: Art at the End of the World', Angelika, 24(3), 2019, p. 185.

30. G.Deleuze, Nietzsche and Philosophy (London: Continuum, 2006), p. 66.

31. Deleuze, Nietzsche, p. 66.

32. Deleuze, Nietzsche, p. 66.

33. Deleuze, Nietzsche, p. 66.

34. Deleuze, Nietzsche, p. 66.

35. Colebrook, 'Cut in Relationality'.

36. D.Bissell and A.Gorman-Murray, 'Disoriented Geographies: Undoing Relations, Encountering Limits', Transactions of the Institute of British Geographers, 44(4), 2019, pp. 707-20.

37. D.Bissell, 'The Anaesthetic Politics of Being Unaffected: Embodying Insecure Digital Platform Labour', Antipode, EPub ahead of print 14 October 2021.

38. M.Hardt, 'The Power to be Affected', International Journal of Politics, Culture and Society, 28, 2015, p. 220.

39. Deleuze, Nietszche, p. 1.

40. M.Hardt, 'Power to be Affected', p. 222.

41. Dekeyser and Jellis, 'Besides Affirmationism', p. 318.

42. B.Anderson, 'Affect and Critique: A Politics of Boredom', Environment and Planning D: Society and Space, 39(2), 2021, p. 208.

43. P.Noxolo, “"My Paper, My Paper": Reflections on the Embodied Production of Postcolonial Geographical Responsibility in Academic Writing', Geoforum, 40(1), 2008, pp. 55-65.

44. Zhang, 'Unaffirmable'.

45. Ruez and Cockayne, 'Feeling Otherwise'.

46. S.Ahmed, The Promise of Happiness (Durham and London: Duke University Press, 2010), p. 214.

47. Ruez and Cockayne, 'Feeling Otherwise', p. 91.

48. Ahmed, Promise of Happiness, p. 214.

49. Ahmed, Promise of Happiness, p. 240.

50. Davies et al., 'Reclaiming failure'; E.Harrowell, T.Davies and T.Disney, 'Making Space for Failure in Geography Research', The Professional Geographer, 70(2), 2018, pp. 230-8.

51. J.Turner, '0-39\%: The Beginning of an Infrastructure of Failure in Academia', Emotion, Space and Society, 35, 2020, pp. 1-5; Anderson, 'Failures of Interest'.

52. Ruez and Cockayne, 'Feeling Otherwise'; Zhang, 'Unaffirmable'; Anderson, 'Affect and Critique'. See responses to Ruez and Cockayne: L.Kern, 'Stories We Tell', Dialogues in Human Geography, 11(1), 2021, pp. 122-5; J.Linz and A.Secor, 'Undoing Mastery: With Ambivalence?', Dialogues in Human Geography, 11(1), 2021, pp. 108-11; E.Wilkinson and J.Lim, 'Life From the Fragments: Ambivalence, Critique, and Minoritarian Affect', Dialogues in Human Geography, 11(1), 2021, pp. 112-6.

53. E.K.Sedgwick, 'Paranoid Reading and Reparative Reading, or, You're so Paranoid, You Probably Think This Essay is About You', in E.K.Sedgwick (ed.), Touching Feeling: Affect, Pedagogy, Performativity (Durham and London: Duke University Press, 2003), p. 124.

54. Ruez and Cockayne, 'Feeling Otherwise', p. 95.

55. A.Cvetkovich, Depression: A Public Feeling (Durham and London: Duke University Press, 2012), p. 2; Ahmed, Promise of Happiness; Davies et al., 'Reclaiming Failure'; J.E.Muñoz, 'Feeling Brown, Feeling 
Down: Latina Affect, the Performativity of Race, and the Depressive Position', Signs: Journal of Women in Culture and Society, 31(3), 2006, pp. 675-88; N.Osborne, 'For Still Possible Cities: A Politics of Failure for the Politically Depressed', Australian Geographer, 50(2), 2019, pp. 145-54; Wilkinson and Ortega-Alcázar, 'Right to be Weary'.

56. J.D.Todd, 'Experiencing and Embodying Anxiety in Spaces of Academia and Social Research', Gender, Place \& Culture, 28(4), 2021, p. 491.

57. For related arguments in the context of academic failure, see: Horton, 'Failure Failure'; N.Clare, 'Can the Failure Speak? Militant Failure in the Academy', Emotion, Space and Society, 33, 2019, pp. 1-4.

58. Sedgwick, 'Paranoid Reading', p. 137.

59. Linz and Secor, 'Undoing Mastery', p. 110.

60. Ruez and Cockayne, 'Feeling Otherwise', p. 89.

61. M.Rose, D.Bissell and P.Harrison, 'Negative Geographies', in D.Bissell, M.Rose and P.Harrison (eds), Negative Geographies: Exploring the Politics of Limits (Lincoln: University of Nebraska Press, 2021), pp. 1-38; Wilkinson and Lim, 'Fragments'.

62. Harrison, 'After Affirmation', p. 292.

63. Romanillos, 'Mortal questions'; J.L.Romanillos, 'Geography, Death, and Finitude', Environment and Planning A: Economy and Space, 43(11), 2011, pp. 2533-53; J.L.Romanillos, 'Nihilism and Modernity: Louis-Ferdinand Celine's 'Journey to the End of the Night", Transactions of the Institute of British Geographers, 40, 2015, pp. 128-39.

64. Dekeyser and Jellis, 'Besides Affirmationism'.

65. G.Bataille cited in M.Surya, Georges Bataille: An Intellectual Biography (London: Verso Books, 2002), p. 300 .

66. J.-L.Nancy, Hegel: The Restlessness of the Negative (Minneapolis: University of Minnesota Press, 2002).

67. C.Nash, 'Performative in Practice: Some Recent Work in Cultural Geography', Progress in Human Geography, 24, 2000, pp. 653-64.

68. S.Atkinson and K.Scott, 'Stable and Destabilised States of Subjective Well-Being: Dance and Movement as Catalysts of Transition', Social \& Cultural Geography, 16(1), 2015, pp. 75-94.

69. D.Coole, Negativity and Politics. Dionysus and Dialectics From Kant to Poststructuralism (London: Routledge, 2000).

\section{Author biographies}

Thomas Dekeyser is a cultural geographer and urban ethnographer who is currently a British Academy Postdoctoral Fellow at the Centre for the GeoHumanities at Royal Holloway, University of London. His research interests revolve around technological power, urban subcultures, the politics of refusal, and theories of pessimism and nihilism. He has published on these topics in journals including Transactions of the Institute of British Geographers, Environment and Planning A, Radical Philosophy, and Theory, Culture \& Society, and is currently writing a monograph tentatively titled Techno-nihilism: a geo-philosophical history of technological refusal.

Anna Secor is Professor of Human Geography at Durham University, UK. Her research seeks to understand the dynamic entanglement of difference, politics and space in everyday life in Turkey and in refugee resettlement to the US. Her collaborative research in these areas has been funded by the National Science Foundation and the National Geographic Society. She is co-editor of The Wiley Blackwell Companion to Political Geography (Wiley, 2015) and A Place More Void (University of Nebraska Press, 2021) and an editor of the journal cultural geographies (Sage).

Mitch Rose is Senior Lecturer in the Department of Geography and Earth Sciences at Aberystwyth University. His research interests are in cultural geography, cultural theory and the history and culture of Egypt and the Middle East. He is a co-editor of Negative Geographies: Exploring the Politics of Limits (2021).

David Bissell is Associate Professor and Australian Research Council Future Fellow in Geography at the University of Melbourne. David is a cultural geographer who undertakes qualitative research on mobile lives 
and technological futures. His current and recent projects explore the impact of digital on-demand mobile work on cities; how automation is changing workplaces; and how households respond to mobile work practices. He is author of Transit Life: How Commuting Is Transforming Our Cities (MIT Press, 2018) and coeditor of Negative Geographies: Exploring the Politics of Limits (U Nebraska Press, 2021).

Vickie Zhang is a postdoctoral fellow at Guangzhou University in China, working across the Center for Human Geography and Urban Development, and the Guangdong Provincial Center for Urban and Migration Studies. Vickie is a cultural geographer interested in the changing lives of workers in transforming economies. She explores economic transitions as embodied experiences through qualitative methods and postphenomenological theories of embodiment, with a particular focus on China and Australia. She has published in journals including Environment and Planning D: Society and Space, cultural geographies and GeoHumanities.

Jose Luis Romanillos is Senior Lecturer in Human Geography in the College of Life and Environmental Sciences, University of Exeter. His research has explored the geographical significance of philosophical positions from figures like Hegel, Heidegger, and Bataille to re-consider the spatial dimensions of death and finitude, and the geographical work of literature. He is currently writing a book project, What is geophilosophy?, which develops a Hegelian reading of the history and philosophy of geographical thought. 


\section{University Library}

\section{- M M I N E R VA A gateway to Melbourne's research publications}

Minerva Access is the Institutional Repository of The University of Melbourne

\section{Author/s:}

Dekeyser, T;Secor, A;Rose, M;Bissell, D;Zhang, V;Romanillos, JL

Title:

Negativity: space, politics and affects

Date:

2021-11-17

Citation:

Dekeyser, T., Secor, A., Rose, M., Bissell, D., Zhang, V. \& Romanillos, J. L. (2021).

Negativity: space, politics and affects. CULTURAL GEOGRAPHIES, 29 (1), pp.5-21. https:// doi.org/10.1177/14744740211058080.

Persistent Link:

http://hdl.handle.net/11343/292056 